\title{
EFFICACY OF A VERY BRIEF PERSONALIZED SEXUAL HEALTH PREVENTION PROGRAM
}

Sarah R. Edwards

University of North Dakota, Grand Forks, ND, USA

E-mail: sarah.edwards@und.edu

Verlin B. Hinsz

North Dakota State University, Fargo, ND, USA

E-mail: verlin.hinsz@ndsu.edu

David H. Whitcomb

University of North Dakota, Grand Forks, ND, USA

E-mail: david.whitcomb@und.edu

\begin{abstract}
An estimated 85 million pregnancies were unintended worldwide in 2012, which is $40 \%$ of all pregnancies (Sedgh, Singh, Hussain, 2014). Knowledge about how to use different methods of contraception correctly is vital to their success. The aim of this research was to evaluate the efficacy of an ultra-short, computerized personal feedback intervention to increase 34 college students' knowledge about different methods of contraception and compare them to 34 students who did not receive the intervention. Students who participated in the intervention improved their factual knowledge about contraception and also indicated marginally higher intentions to use condoms in future sexual interactions after the personalized feedback intervention as compared to students in a control condition. Implications for settings in which very brief interventions to improve knowledge regarding contraception and sexually transmitted infection (STI) prevention are desirable are discussed.
\end{abstract}

Key words: college student health, contraception, personalized computerized feedback, STI prevention.

\section{Introduction}

The Center for Disease Control and Prevention (2015) estimates that nearly 20 million people per year are newly infected with a sexually transmitted disease (STD) in the United States alone. The majority of infections occur in adolescents and young adults age 15-24. Having accurate knowledge about sexually transmitted diseases and what contraception can and cannot do (e.g., most contraceptives do not prevent disease infection) is perhaps one of the most vital steps in the prevention of unwanted pregnancies and infections. 


\section{Problem of Research}

While many studies have evaluated methods to enhance motivation to increase sexually responsible behaviors (e.g., use of condoms; Wyatt \& Oswalt, 2011), if students lack adequate knowledge about methods of contraception and how to use them correctly, it is less likely they will be successful at preventing pregnancy and infections. Assessment and prevention programs aimed at promoting the health of college students are becoming widespread across the U. S. and many other countries (Buhi, Marhefka, \& Hoban, 2010). Every year, hundreds of U. S. colleges and universities collect data from over 100,000 students on a wide variety of health issues, including sexual health (American College Health Association, 2015; 2016). Colleges often invest a substantial amount of resources into such programs with the aim to widely disseminate educational material related to sexual health and pregnancy prevention to students. Lack of personal relevance, difficulty of access, and other factors, however, can impede the effectiveness of printed or online educational material without interactive components. Psychoeducation efforts in individual or group settings have advantages in that they can be more personalized and can attempt to engage students more with the material, however, they also require manpower in form of a qualified presenter and require a time investment both from the facilitators and on part of the students attending (Buhi, Daley, Fuhrmann, Smith, 2009).

\section{Research Focus}

The purpose of this research is to evaluate the efficacy of a novel short interactive approach with young adults, consisting of personalized computerized feedback to increase factual knowledge about different methods of contraception and increase intentions to use condoms in future sexual encounters. As part of a widespread "abstinence only" movement, many states in the United States, as well as some non-European countries, do not provide education about how to prevent STDs or pregnancies in public schools other than telling students to refrain from sexual activity until marriage (Wiley \& Wilson, 2009). However, a recent multinational study concluded that 15 years of data on programs in 22 Sub-Sarahan African countries determined that funding for abstinence and faithfulness based programs was not associated with reduced HIV infection rates (Lo, Lowe, \& Bendavid, 2016). As many young adults choose to engage in sexual activity before entering into a long-term, committed relationship, increasing knowledge about preventing unwanted pregnancy and sexually transmitted diseases is vital to improve health and wellbeing of this demographic.

A leading behavioral health method of reducing risky behaviors is Personalized Normative Feedback (PNF; Collins, Carey, \& Sliwinski, 2001). Personalized feedback in our study is modeled after personalized normative influence with the exception that, instead of norms, factual knowledge is presented to participants along with their own answers to knowledge-based questions. Instead of simply reading educational materials or attending a lecture, personalized feedback is delivered on a computer screen right after participants make judgments about a fact or norm along with their own response so students can immediately see both. The student therefore has the opportunity to directly compare his or her own belief with factual data. PNF interventions commonly provide students with descriptive norms and consequence norms for the targeted behavior (e.g., alcohol use; Brett, Leavens, Miller, Lombardi, \& Leffingwell, 2016). Students therefore have an opportunity to learn how their behavior compares with their peers in terms of frequency, intensity, other markers, and thereby evaluate the acceptability of their own behavior in reference to a social comparison group. Motivation to change undesirable behaviors may increase as a result. Normative influence has been shown to be effective in reducing a variety of undesirable behaviors such as alcohol use (Palfai, Zisserson, \& Saitz, 2011 ); gambling (Neighbors et al., 2016), and a variety of behaviors, including substance use and unprotected sex, that increase risk for HIV infection (Albarracin, Gillette, Earl, Glasman, Durantini, \& Ho, 2005; Lewis, Lee, Patrick, \& Fossos, 2007). In the present study we investigate whether personalized factual feedback can be equally effective. Therefore, it is hypothesized that (1) personalized feedback will increase factual knowledge about different methods of contraception in students, and (2) personalized feedback will increase intentions to use condoms in future sexual interactions. 


\section{Methodology of Research}

\section{General Background of Research}

To evaluate the efficacy of the personalized computerized feedback, the research employed a 2 (treatment/control) x 2 (time) mixed design. The students were randomly assigned to either receive the here reported STD/condom use intervention or took part in a computerized intervention to produce more prosocial attitudes around dating violence, reported elsewhere (Edwards \& Hinsz, in preparation).

\section{Sample of Research}

Participants consisted of 72 university students who received extra credit in a lower level undergraduate psychology course in exchange for their participation in this research. All research was approved by the institutional human subject protection board. A priori power analysis using GPower 3.1 determined a sample size of 66 is needed to detect a medium effect (.25) at a power level of .81 and alpha of .05 . Therefore, 72 students satisfied the sample size requirement for the current study. Students were undergraduates at a US institution, and $86 \%$ identified as white, US citizens, consistent with the demographics of the rural, Midwestern United States location of the university. The majority were in their first or second year of university studies, with a mean age of $19.5, \mathrm{SD}=1.4$. Four participants did not return for the second assessment, which left 68 students for the final analyses.

\section{Instrument and Procedures}

Students in both conditions initially completed a ten question assessment of their factual knowledge of the correct use of different types of contraception such as the pill, diaphragms, and condoms. This set of questions was part of a larger data collection effort around the topic of healthy relationships. All items assessed beliefs in a given fact on a 7-point scale. Intentions to use condoms in future sexual encounters were also assessed, using a 1-7 scale ranging from having no intentions to being sure to use condoms in the next sexual encounter.

Several days later the students in the experimental condition were exposed to the computerized personalized feedback with regard to accurate knowledge about contraception and condom use. This consisted of 16 distinct factual pieces of information about condom and other contraceptive use and STIs. Students answered a question regarding contraception such as "When used with spermicide, the diaphragm is over $90 \%$ effective." After students had entered their answer, their response was displayed along with the correct answer and an explanation. The intervention took about 2-4 minutes. The control condition received personalized feedback aimed to prevent dating aggression. Three to ten days after the intervention, students returned to complete the measures testing their knowledge of contraception methods and intentions to use condoms again.

\section{Data Analysis}

Hypotheses one and two were evaluated by running 2 mixed ANOVAs with factual knowledge and intentions to use condoms being the dependent variables, respectively. SPSS 22 was used for data analysis.

\section{Results of Research}

To test hypothesis one, that individualized computerized feedback improves students' factual knowledge of contraception, a 2 (experimental/control) x 2 (pre/post) mixed ANOVA was conducted. Means for the intervention and control group can be seen in figure 1 . 


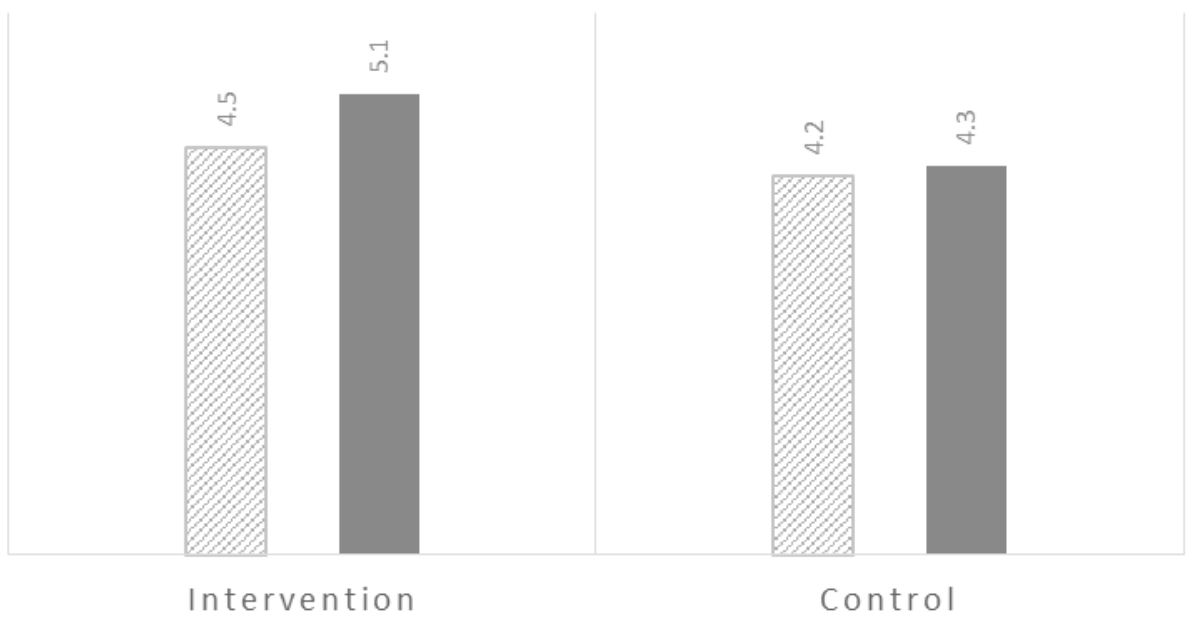

\section{Figure 1: $\quad$ Means of Knowledge of Contraception Use and STIs by condition and time.}

A significant interaction of time and condition confirmed students in the experimental condition increased their factual knowledge about contraception after the personalized feedback more so than students in the control condition, $\mathrm{F}(1,66)=4.82, \mathrm{p}<.05$, partial $\eta^{2}=.07$, with the main effect for time, $\mathrm{F}(1,66)=10.13, \mathrm{p}<.01$, partial $\eta^{2}=.13$ also reaching significance.

Another 2 (experimental/control) x 2 (pre/post) mixed ANOVA was conducted to evaluate hypothesis two. Means for the intervention and control group are displayed in figure 2.

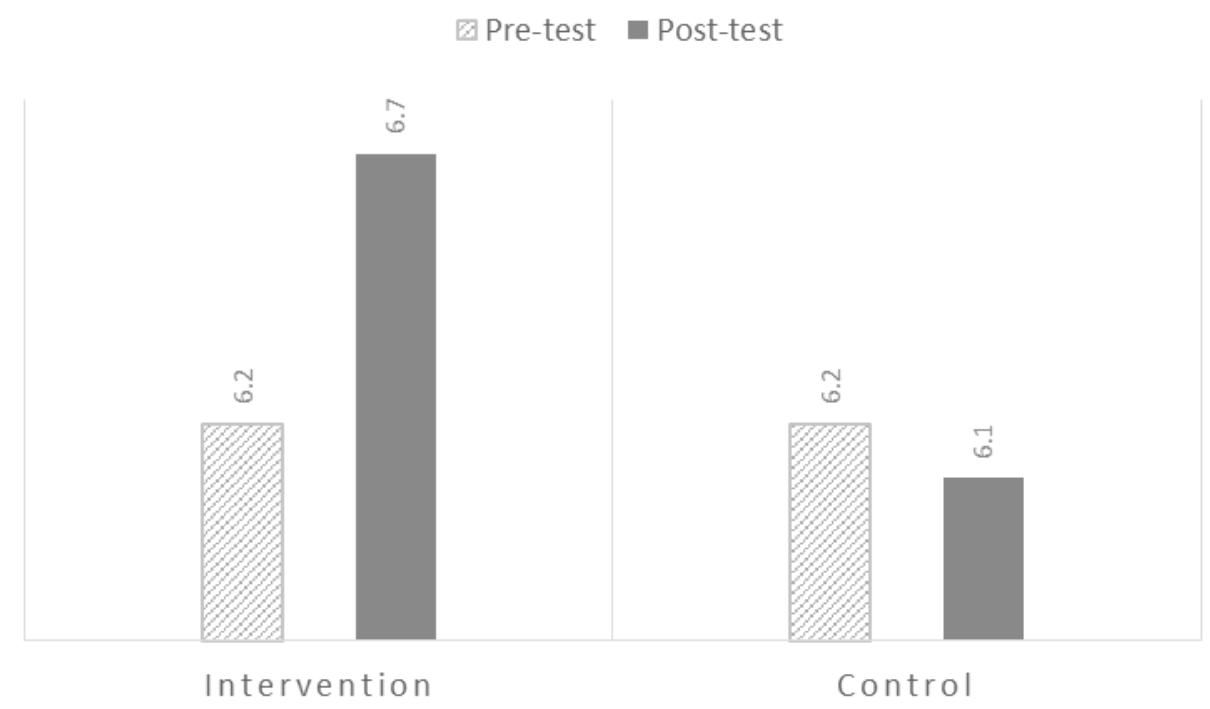

Figure 2: Means for intentions to use condoms by condition and time.

There was no significant main effect, and the interaction was only marginally significant, $\mathrm{F}$ ( 1 , $66)=3.38, p=.07$, partial $\eta^{2}=.05$. Further inspection of the data showed an effect in the expected direction, however, 24 students had already indicated the strongest intentions to use condoms in their next sexual encounter during time one, leaving no room for further improvement through an intervention. 


\section{Discussion}

These results demonstrate that a very brief, personalized intervention can increase students' knowledge and future intentions to protect themselves against unwanted pregnancy and disease. Although some major universities already use a comprehensive prevention program at orientation (e.g., HealthyHorns, 2015), such programs are lacking on many campuses. Because of the shortness and ease of administration of such intervention, it could be easily implemented in college orientation programs.

Whereas sexual health programs on campus are often as long as an hour or more, the initial intervention and follow-up feedback session described in the current study last less than five minutes each for the typical college student. Using a computerized approach keeps program costs low as there is no need to gather in large groups or incur the labor and time intensive expenses of one-on-one instruction (Lewis \& Neighbors, 2015). The brevity and simplicity are features that are likely to appeal especially on campuses that have limited resources to initiate or maintain health promotion programs. Even during an event-packed orientation, students are likely to have the time and attention to devote a few minutes to a program aimed at assessing and improving their sexual knowledge and health. During other times of the year, having the intervention available online at sites of student affairs units such as health services or the counseling center would continue to provide easy access for self-administration.

A recent national survey found most college students are sexually active and that among those who report having at least one sexual partner within the past 12 months, the mean number of sexual partners for men is 2.73 whereas for women it is 2.01 (American College Health Association, 2015). The frequency at which many college students engage in sex with a new partner suggests that the risks for STIs and pregnancy are high if students have not acquired accurate health information. Our research complements existing research on computerized normative influence approaches to affect behavioral changes (e.g. Albarracin, Gillette, Earl, Glasman, Durantini, \& Ho, 2005; Lewis, Lee, Patrick, \& Fossos, 2007; Palfai, Zisserson, \& Saitz, 2011) and demonstrates the potential usefulness to improve knowledge via an interactive computerized feedback intervention. However, such a brief intervention should not serve as a stand-alone prevention program. To achieve lasting behavioral changes, one has to target knowledge, attitudes, and motivation alike. This research is interesting in that it demonstrates a very brief prevention that can easily be integrated in existing college programs, can increase knowledge on the subject of contraception, and proper knowledge is a necessary precursor to effective contraception use.

\section{Conclusions}

College is an opportune time to reach traditional-age students who may not have received any sexual health education previously. As students leave a sometimes insulated, protected home community and start to explore their sexuality in a college environment without close parental supervision, lack of sexually-related knowledge could become a greater detriment. The learning of personally meaningful information on a topic that is considered very private and sensitive can be enhanced via the privacy of a computer interface. Furthermore, the specific sexual topic and the tone of messages conveyed could vary from one setting or circumstance to another. For example, to tailor the content to the specific needs of a school or program, other factual knowledge related to sexually transmitted diseases (such as recognition of symptoms, need for a physical exam or blood test) could be conveyed to students via personalized feedback. 


\section{References}

Albarracin, D., Gillette, J. C., Earl, A. N., Glasman, L. R., Durantini, M. R., \& Ho, M. H. (2005). A test of major assumptions about behavioral change: A comprehensive look at the effects of passive and active HIV-prevention interventions since the beginning of the epidemic. Psychological Bulletin, $131,856-897$.

American College Health Association (2015). American College Health Association-National College Health Assessment II: Reference group executive summary spring 2015. Hanover, MD: American College Health Association.

American College Health Association (2016). American College Health Association-National College Health Assessment II: Reference group executive summary fall 2015. Hanover, MD: American College Health Association.

Buhi, E. R., Daley, E. M., Fuhrmann, H. J., \& Smith, S. A. (2009). An observational study of how young people search for online sexual health information. Journal of American College Health, 58 (2), 101111. doi:10.1080/07448480903221236.

Buhi, E. R., Marhefka, S. L., \& Hoban, M. T. (2010). The State of the Union: Sexual health disparities in a national sample of US college students. Journal of American College Health, 58 (4), 337-346. doi:10.1080/0744848090350178.

Brett, E. I., Leavens, E. L., Miller, M. B., Lombardi, N., \& Leffingwell, T. R. (2016). Normative perceptions of alcohol-related consequences among college students. Addictive Behaviors, 5816-20. doi:10.1016/j. addbeh.2016.02.008.

Centers for Disease Control and Prevention (2015). Sexually transmitted disease surveillance 2014. Atlanta, GA: U.S. Department of Health and Human Services.

Collins, S. E., Carey, K. B., \& Sliwinski, M. J. (2002). Mailed personalized normative feedback as a brief intervention for at-risk college drinkers. Journal of Studies on Alcohol, 63 (5), 559-567.

Edwards, S. E., \& Hinsz, V. B. (In preparation). Combining Normative Influence and Behavioral Skills Training to Prevent Dating Violence.

HealthyHorns (2015). Think about it. Retrieved from the University of Texas at Austin University Health Services website: http://www.healthyhorns.utexas.edu/thinkaboutit/.

Lewis, M. A., Lee, C. M., Patrick, M. E., \& Fossos, N. (2007). Gender-specific normative misperceptions of risky sexual behavior and alcohol-related risky sexual behavior. Sex Roles, 57 (1-2), 81-90. doi:10.1007/s11199-007-9218-0.

Lewis, M. A., \& Neighbors, C. (2015). An examination of college student activities and attentiveness during a web-delivered personalized normative feedback intervention. Psychology of Addictive Behaviors, 29 (1), 162-167. doi:10.1037/adb0000003.

Lo, N. C., Lowe, A., \& Bendavid, E. (2016). Abstinence funding was not associated with reductions In HIV risk behavior in Sub-Saharan Africa. Health Affairs, 35 (5), 856-863. doi:10.1377/hlthaff.2015.0828.

Neighbors, C., Lewis, M. A., LaBrie, J., DiBello, A. M., Young, C. M., Rinker, D. V., \& ... Larimer, M. E. (2016). A multisite randomized trial of normative feedback for heavy drinking: Social comparison versus social comparison plus correction of normative misperceptions. Journal Of Consulting And Clinical Psychology, 84 (3), 238-247. doi:10.1037/ccp0000067.

Palfai, T. P., Zisserson, R., \& Saitz, R. (2011). Using personalized feedback to reduce alcohol use among hazardous drinking college students: The moderating effect of alcohol-related negative consequences. Addictive Behaviors, 36 (5), 539-542. doi:10.1016/j.addbeh.2011.01.005.

Sedgh, G., Singh, S., \& Hussain, R. (2014). Intended and unintended pregnancies worldwide in 2012 and recent trends. Studies in Family Planning, 45 (3), 301-314.

Wiley, D., \& Wilson, K. (2009). Just say don’t know: Sexuality education in Texas public schools. Retrieved from Texas Freedom Network Education Fund website: http://a.tfn.org/site/DocServer/ SexEdRort09_web.pdf?docID=981. 
OF PSYCHOLOGY

IN THE $21^{\text {st }}$ CENTURY

Vol. 10, No. 1, 2016

12

Wyatt, T. J., \& Oswalt, S. B. (2011). Letting students be innovative! Using mini-grants to fund student-designed HIV/AIDS education. Health Promotion Practice, 12 (3), 414-424. doi:10.1177/1524839909348745.

Advised by Vincentas Lamanauskas, Šiauliai University, Lithuania

Received: June 10, 2016

Accepted: June 29, 2016

Sarah R. Edwards Ph.D., Assistant Professor of Counselling Psychology, University of North

Dakota, Stop 8255, Grand Forks, ND 58202, USA.

E-mail: sarah.edwards@und.edu

Website: https://und.edu/faculty/sarah.edwards

Verlin B. Hinsz Ph.D., Professor of Psychology, North Dakota State University, Fargo, ND 58105, USA.

E-mail: verlin.hinsz@ndsu.edu

Website: https://www.ndsu.edu/faculty/hinsz/

David H. Whitcomb Ph.D., Assistant Professor of Counselling Psychology, University of North Dakota, Stop 8255, Grand Forks, ND 58202, USA.

E-mail: david.whitcomb@und.edu

Website: https://und.edu/faculty/david.whitcomb 